\title{
Evaluation of Noise Levels in Different Industrial Sectors within the Gaza Strip: A Pilot Study
}

\author{
Abed Schokry \\ Department of Industrial Engineering, Faculty of Engineering, Islamic University, P. O. B. 108 Gaza, Palestinian Territories
}

\begin{abstract}
Noise presents health and social problems in industrial operations and is mainly related to machinery use. Noise is an important factor that affects work environment, and consequently affects both workers' health and efficiency. The US OSHA (Occupational Safety and Health Administration) specify six on-the-job physical hazards to health, noise is one of those hazards. There is little or no information about occupational noise exposure of workers within industrial and manufacturing sectors in the Gaza Strip. This is due to the difficulty of conducting noise exposure surveillance in such occupations and the lack of awareness regarding this issue. The objective of the current study is to evaluate the exposure of workers in different industrial sectors to occupational noise using a combined measurement and questionnaire approach The present study was conducted in different utilities industries in the Gaza Strip, in order to evaluate the noise levels at those factories and to develop awareness campaign among those workers. From the obtained data, it can be seen that almost all workers are exposed to higher noise levels than the recommended one by OSHA. Therefore it is necessary to start awareness campaign which informs the workers about noise as an occupational hazard.
\end{abstract}

Key words: Sound level meters, industrial noise pollution, occupational noise exposure, periodical hearing tests programs, noise induced hearing loss.

\section{Introduction}

Noise exposure at work remains a significant occupational hazard in industrial plants. What is noise? According to the AEPA (American Environmental Protection Agency) noise is any unwanted or disturbing sound [1]. Occupational exposure to excessive noise has been identified as a very prominent hazard encountered in different industrial sectors, both in developing countries and in industrialized countries. Manufacturing accounts for the greatest number of exposed employees, for example steel factories, carpentries, marble and concrete plants. NIHL (Noise induced hearing loss) as a result of exposure to high noise levels is well documented in the literature [2-9]. According to the WHO (World Health Organization), there are an estimated 250 million persons suffering from hearing loss [10]. It has to be noticed that an accurate estimation of the workers affected by NIHL is

Corresponding author: Abed Schokry, assistant professor, research fields: safety, ergonomics and quality. E-mail: aschokry@iugaza.edu.ps. difficult for the following reasons: long latency period, the problem of aging, and non-occupational exposure (life style).

"Every year, approximately 30 million people in the US are occupationally exposed to hazardous noise. Noise-related hearing loss has been listed as one of the most prevalent occupational health concerns in the US for more than 25 years" [11].

In addition, exposure to excessive noise also leads to non-auditory effects including: annoyance and stress, the masking of warning signals resulting in accidents, interference with communications among workers, high blood pressure, sleep disorders and decrease in performance [12-17]. However, few studies have addressed these non-auditory effects among workers in developing countries $[8,18]$.

NIHL can be entirely prevented by engineering controls, by administrative controls, or by the regular wearing of HPDs (Hearing protection devices) [19].

In Palestine, and especially in the Gaza Strip, the rate of industrialization is still suffering from Israeli 
occupation. On the one hand, and from closure, i.e. Israeli imposed restrictions on movement that apply to Palestinian goods and citizens under the pretext of security; on the other hand, The established industries are small family firms, and most workshops are small. The workforce of these industries exposed to occupational hazards and consequently is at high risk of work-related diseases and injuries, for example hearing loss.

There is as yet no department of occupational disease within the Palestine Ministry of Health. Therefore no data exist regarding this issue in the Palestinian context (particularly in Gaza Strip). Lack of legislation has a negative impact on the safety and health of workers.

\section{Study Objectives}

The main objectives of this pilot study are:

(1) To measure levels of noise and see how these compare with OSHA standards;

(2) To determine the prevalence rate of noise annoyance among the study population;

(3) Finally to evaluate the awareness and practice of workers towards hazardous levels of noise.

\section{Materials and Methodology}

3.1 Selection of the Different Industrial Sectors within the Gaza Strip

The study was conducted in different industrial sectors, marble and stone factories, carpentries, plastics companies, food processing factories (bakeries). In each sector, diverse factories were randomly selected. The selected factories were grouped as follow:

Group A: plastics, stone and metal factories;

Group B: carpentries;

Group C: food processing, bakery.

Noise levels were measured and documented and 80 questionnaires were prepared for structured interviews. The questions were written in Arabic. The questions were formulated to obtain data regarding: awareness about job-related hazards, awareness about health effects of job-related hazards, safety training, awareness about effects of noise on health and about noise prevention techniques, and about noise and annoyance. Questions about age, education, and years of work experience were not collected.

\subsection{Data Collection}

Questionnaire interviews were carried out and collected. The questionnaire was a structured interview to evaluate the practice of work place safety in general and specifically towards noise within each factory. Questions were about noise annoyance, as well as about awareness of NIHL. A total number of 66 interviewed workers were distributed as follow:

Group A: 20 persons;

Group B: 30 persons;

Group C: 16 persons.

The interviewed persons were mostly workers but also some owners.

In addition, the author's observations over a three-year period were incorporated.

\subsection{Noise Measurement}

The tool used to measure noise was an AEMC CA832 sound level meter ( $35 \mathrm{~dB}$ to $80 \mathrm{~dB}$ ), conformance to EU standard. It was assessesed sound ambiences or annoyances in accordance with international safety and quality standards. At each factory noise measurements were taken at strategic locations at head height. Six to eight measurements were taken each time for Leq Max (the sound pressure level in $\mathrm{dB}$, equivalent to the total sound energy over a given period of time) and Leq Min and documented. Each time a new factory was visited, the sound level meter was calibrated using a calibrator C.A. 833.

\section{Results Analysis and Discussion}

\subsection{Results}

Table 1 contains the results of noise measurements at the different factories. Table 1 and Fig. 1 show that all values of the mean Leq Min and the mean of Leq Max 
Table 1 The overall mean noise levels in different industrial sectors.

\begin{tabular}{llllll}
\hline Industry & Industrial sector & N & $\begin{array}{l}\text { Leq } \\
\text { mean (SD) (dBA) }\end{array}$ & $\begin{array}{l}\text { Minimum Leq } \\
\text { mean (dBA) }\end{array}$ & $\begin{array}{l}\text { Maximum Leq } \\
\text { mean (dBA) }\end{array}$ \\
\hline & 1. Plastic factory (1) & 6 & $101.9(3.2)$ & 100.80 & 102.70 \\
2. Plastic factory (2) & 6 & $104.2(1.5)$ & 103.30 & 105.20 \\
Group A: plastics, stone & 3. Metal factory (1) & 6 & $105.4(1.9)$ & 104.10 & 106.50 \\
and metal factories & 4. Stone factory (1) & 6 & $93.8(2.8)$ & 93.20 & 94.00 \\
& 5. Stone factory (2) & 6 & $93.6(1.2)$ & 92.70 & 94.20 \\
& 6. Stone factory (3) & 6 & $93.9(1.8)$ & 93.70 & 94.20 \\
\hline & 7. Carpentry (1) & 8 & $102.5(2.8)$ & 100.60 & 103.40 \\
& 8. Carpentry (2) & 8 & $97.5(1.7)$ & 96.30 & 98.30 \\
9. Carpentry (3) & 8 & $90.6(2.5)$ & 88.20 & 92.30 \\
Group B: carpentries & 10. Carpentry (4) & 8 & $93.5(2.6)$ & 91.60 & 94.30 \\
& 11. Carpentry (5) & 8 & $90.7(3.2)$ & 87.30 & 92.20 \\
12. Carpentry (6) & 8 & $88.9(3.0)$ & 86.30 & 91.40 \\
& 13. Carpentry (7) & 8 & $89.8(2.2)$ & 88.30 & 91.00 \\
14. Carpentry (8) & 8 & $90.7(4.2)$ & 88.50 & 91.50 \\
15. Carpentry (9) & 8 & $89.9(3.8)$ & 87.30 & 90.80 \\
\hline proup C: food & 16. Bakery (1) & 7 & $97.6(4.1)$ & 93.50 & 98.00 \\
17. Bakery (2) & 7 & $90.1(2.3)$ & 85.70 & 90.30 \\
\hline
\end{tabular}

*N: Number of noise measurements.

**SD: Standard deviation.

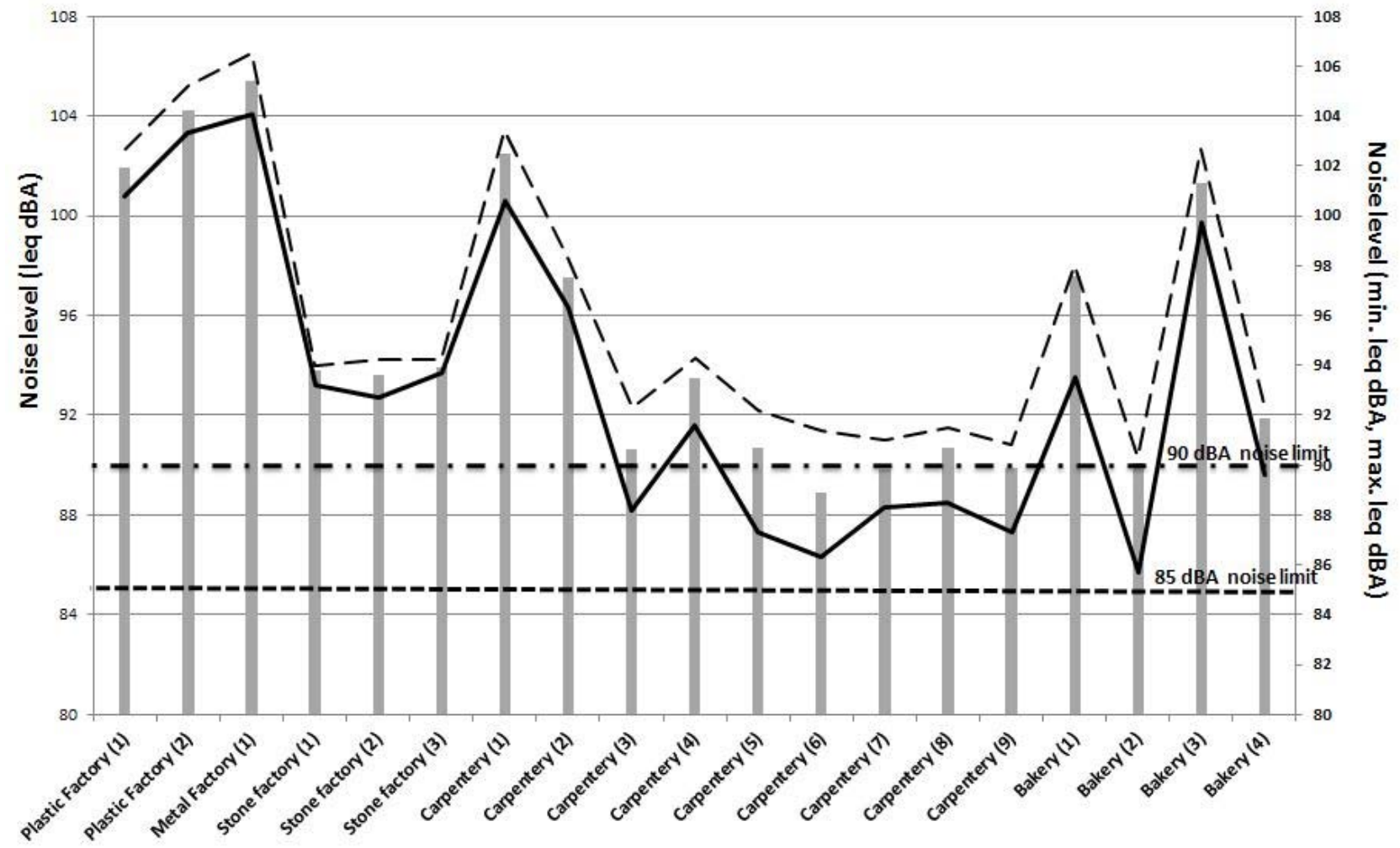

Fig. 1 Noise levels in different industrial sectors. 
exceed the $85 \mathrm{~dB}(\mathrm{~A})$ criterion recommended by the USA-ACGIH (American conference of governmental industrial hygienists) [20-22] as well as recommended by the EU directive [23]. This means that all workers are exposed to daily Leq above the maximum exposure limit of $90 \mathrm{~dB}$ (A) published by OSHA as seen in Table 2 [24]. Only in a few carpentries the Leq Min is below $90 \mathrm{~dB}(\mathrm{~A})$.

Table 3 contains the answers to questions regarding awareness about occupational hazards, and whether noise has annoyance effect, awareness about health effects of noise, and whether workers have been informed about occupational hazards, and whether they have attended a training course about occupational health and safety. Only a small percentage of workers wore HPDs. The majority of workers experienced a certain degree of noise annoyance and revealed that they were accustomed to this noise. In addition only a small minority of workers were aware of the negative impact of being exposed to noise for longer periods of time on a daily basis. Very few workers were informed or trained regarding protection against occupational hazards, especially noise.

\subsection{Discussion}

Exposure to noise was unavoidable in all the industrial plants visited for this research. And yet it is both feasible and inexpensive to reduce the negative impacts of noise exposure. Table 1 contains the noise levels reported in this pilot study (85-106.5 dBA). It can be seen that the daily noise exposure exceeds the maximum OSHA exposure limit of $90 \mathrm{~dB}$ (A) in all areas except in some carpentries. But when the permissible noise exposure limit is taken to be $85 \mathrm{~dB}(\mathrm{~A})$, then almost all the measured and documented results exceed this limit. In other words, workers are at high risk of hearing loss due to daily exposure to excessive noise.

No one should or need lose his/her hearing as a result of his/her occupation or working environment. Hearing loss can have profound social affects, such as isolation and personality change, psychological affects, such as anger, frustration and depression, and can completely change the dynamics of family life and friendships with adverse affects such as denial, avoidance and isolation. Noise has been identified as the most pervasive hazard in the workplace. It is therefore essential to protect workers from avoidable NIHL. The first line of defense should be engineering controls, both source and path, and administrative controls, respectively referred to as moving the hazard and removing the

Table 2 OSHA's permissible noise exposure limits.

\begin{tabular}{ll}
\hline Noise level & Exposure limit \\
\hline $90 \mathrm{dBA}$ & $8.0 \mathrm{~h}$ \\
$92 \mathrm{dBA}$ & $6.0 \mathrm{~h}$ \\
$95 \mathrm{dBA}$ & $4.0 \mathrm{~h}$ \\
$97 \mathrm{dBA}$ & $3.0 \mathrm{~h}$ \\
$100 \mathrm{dBA}$ & $2.0 \mathrm{~h}$ \\
$102 \mathrm{dBA}$ & $1.5 \mathrm{~h}$ \\
$105 \mathrm{dBA}$ & $1.0 \mathrm{~h}$ \\
$110 \mathrm{dBA}$ & $30 \mathrm{~min}$ \\
$115 \mathrm{dBA}$ & $15 \mathrm{~min}$ \\
\hline
\end{tabular}

Table 3 Distribution of workers according to their response to: noise annoyance, questions of awareness, having received information and training.

\begin{tabular}{lllllll}
\hline \multirow{2}{*}{ Statement } & \multicolumn{2}{c}{ Group A (20) } & \multicolumn{2}{c}{ Group B (30) } & \multicolumn{2}{c}{ Group C (16) } \\
\cline { 2 - 6 } & Yes & No & Yes & No & Yes & No \\
\hline Noise has annoyance effect & 14 & 6 & 20 & 10 & 11 & 5 \\
Awareness about occupational hazards & 2 & 18 & 10 & 20 & 2 & 14 \\
Awareness about health effects of noise & 1 & 19 & 12 & 18 & 4 & 12 \\
Awareness about noise prevention methods & 1 & 19 & 6 & 24 & 2 & 14 \\
Have been informed about occupational hazards & 4 & 18 & 10 & 20 & 6 & 10 \\
Have attended a training course about occupational health and safety & 6 & 14 & 6 & 24 & 4 & 12 \\
Use of hearing protection devices (HPDs) & 3 & 17 & 8 & 22 & 5 & 11 \\
\hline
\end{tabular}


worker. So-called HPDs are important but should only be regarded as the third line of defense. Earplugs or earmuffs have the advantage of being inexpensive.

We found that HPDs, which are available, were not used because workers believed they would hinder their ability to hear commands during work and were therefore forgotten or discarded when dressing for work. In many factories workers were simply not provided with hearing protection devices and there was no unawareness of noise hazard. These workers had received no occupational health and safety training.

Some of the visited industrial plants are located very close to, or within, residential areas, which means that residents are also exposed to noise and other hazards. Examples are the noise of electricity generators or the dust from stone and granite factories. In one factory the owner himself had lost about $30 \%$ of his hearing capacity. Nevertheless, neither he nor his employees wore hearing protection devices. The question is why not? What agency is responsible for the protection of employee health? Is it the Ministry of Labor, the Ministry of National Economy, the Ministry of Health, or is it insurance companies, municipalities or NGOs (Non Governmental Organizations) or is it the plant owner or worker himself? Each of the above is responsible for it on his or her own way. Every citizen should have the right to protection against hazards in general and occupational hazards in particular. There are many interventions used, regulations and engineering responses being two of the most common.

A number of very simple engineering or administrative solutions can often be implemented with great success [25, 26] - engineering controls, source controls and path controls (removing the hazard):

Placing noisy machinery in areas away from as many workers as possible;

Maintaining equipment in top operating condition;

Reducing the speed of equipment operation to the slowest practical level;

Moving power equipment out of wooden or metal-frame buildings into masonry structures;
Using forms of damping to reduce vibration and enclosing equipment within barriers;

Using sound-absorbent hoods around machinery;

Administrative controls (removing the worker);

And moving workers to quieter areas; Operating noisy equipment on different shifts.

\section{Conclusions and Recommendations}

This study reveals that noise pollution is presenting health and social problems of workers in different industrial sectors. Workers are exposed to high noise levels, higher than the international acceptable standards for industrial plants. Further studies are recommended to create noise maps enabling a true noise monitoring and management system from which it would be possible to rank noise sources, establishing a detailed noise control action plan. The relevant authorities in Palestine should be more aware and concerned about occupational hazards and the need for implementing effective safety measures for the prevention of possible adverse health effects.

Ideally, a combination of engineering and administrative control measures, with the use of PPE (personal protective equipment), together with training and raised awareness about occupational hazards will reduce risks of occupational injuries and disease.

It is essential to inform workers about this particular problem. A public health campaign should raise awareness of the hazards and propose prevention measures. The use of protective equipment should be legislated. Early screening and treatment would reduce the impact of noise among high-risk groups.

\subsection{Recommendations}

(1) Initiating an information campaign in collaboration between the PFI (Palestinian Federation of Industries), the Ministry of Labor, insurance companies and national (or international) NGO Safety Organizations to inform workers about occupational hazards, especially noise pollution. 
(2) Ensuring that international occupational health and safety standards, procedures and precautions are implemented.

(3) Compliance with the use of personal protective hearing device, together with its proper maintenance and care.

(4) Regular hearing tests (periodic screening for workers at risk) as part of a comprehensive occupational health surveillance program at the workplace. Such screening should be undertaken initially and then periodically.

(5) Development of noise maps for different industrial plants within the Gaza Strip.

Finally, it is very important to start an awareness campaign to inform the population about the risk of loss of hearing through noise pollution. Further research is essential to widen our knowledge of noise pollution and its control.

\section{References}

[1] What is Noise Pollution? Accessed inOctober 10, 2014. http://www.epa.gov/air/noise.html.

[2] Nelson, D. I., Nelson, R. Y., Concha-Barrientos, M. and Fingerhut, M. 2005. "The Global Burden of Occupational Noise-Induced Hearing Loss.” American Journal of Industrial Medicine 48 (6): 446-58.

[3] Concha-Barrientos, M., Campbell-Lendrum, D. and Steenland, K. 2004. Occupational Noise: Assessing the Burden of Disease from Work-Related Hearing Impairment at National and Local Levels. Geneva, World Health Organization (WHO Environmental Burden of Disease Series, No. 9).

[4] Irwin, J. 1997. “Occupational Noise-Induced Hearing Loss.” Occupational Medicine 47: 313-5.

[5] Moon, Y. H. and Kwon, S. P. 1976. "Hearing Impairment Due to Noise in the Kyung-in Industrial Area in Korea.” Yonsei Medical Journal 17: 30-8.

[6] Ologeoge, F. E., Akande, T. M. and Olajide, T. G. 2006. "Occupational Noise Exposure and Sensorineural Hearing Loss among Workers of a Steel Rolling Mill.” European Archives of Oto-Rhino-Laryngology 263: 618-21.

[7] Ashraf, H. D., Younus, M. A., Kumar, P., Siddiqui, M. T., Ali, S. S. and Siddiqui, M. I. 2009. "Frequency of Hearing Loss among Textile Industry Workers of Weaving Unit in Karachi, Pakistan.” Journal Of Pakistan Medical Association 59: 575-9.

[8] Ahmed, H. O., Dennis, J. H., Badran, O., Ismail, M.,
Ballal, S. G. and Ashoor, A. et al. 2001. “Occupational Noise Exposure and Hearing Loss of Workers in Two Plants in Eastern Saudi Arabia." The Annals of Occupational Hygiene 45: 371-80.

[9] Harmadji, S. and Kabullah, H. 2004. "Noise Induced Hearing Loss in Steel Factory Workers.” Folia Medica Indonesiana 40: 171-4.

[10] Mathers, C., Smith, A. and Concha, M. 2000. "Global Burden of Hearing Loss in the Year.” Accessed in October 11, 2014 http://www.who.int/healthinfo/statistics/bod_hearingloss. pdf?ua=1.

[11] Occupational Noise Exposure (OSHA). Accessed October 10, 2014 https://www.osha.gov/SLTC/noisehearingconservation.

[12] Smith, M. E., Kaneand, A. S. and Popper, A. N. 2004 "Noise-induced Stress Response and Hearing Loss in Goldfish.” The Journal of Experimental Biology 207: 427-443.

[13] Cuesdan, L., Teganeanu, S., Tutu, C., Raiciu, M., Carp, C. and Coatu, S. 1977. "Study of Cardiovascular and Auditory Pathophysiological Implications in a Group of Operatives Working in Noisy Industrial Settings.” Psychophysiology 14: 53-61.

[14] Wu, T. N., Chou, F. S. and Chang, P. Y. 1987. "A Study of Noise-induced Hearing Loss and Blood Pressure in Steel Mill Workers.” International Archives of Occupational and Environmental Health 59: 529-36.

[15] Stansfeld, S. A. and Matheson, M. P. 2003. "Noise Pollution: Non-Auditory Effects on Health.” British Medical Bulletin 68: 243-57.

[16] Noise-Non-Auditory Effects. (CCOHS) Accessed in October $10, \quad 2014$ http://www.ccohs.ca/oshanswers/phys_agents/non_audito ry.html.

[17] Dijk, F. J., Souman, A. M. and de V. F. 1987. "Non-Auditory Effects of Noise in Industry. VI. A Final Field Study in Industry." International Archives of Occupational and Environmental Health 59 (2): 133-45.

[18] Saiyed, H. N. and Tiwari, R. R. 2004. "Occupational Health Research in India.” Industrial Health 42: 141-8.

[19] Noise Control and Hearing Conservation Program (University of Toronto). Accessed in October 10, 2014. http://www.ehs.utoronto.ca/Assets/ehs+Digital+Assets/eh s3/policies/Noise.pdf.

[20] American Conference of Governmental Industrial Hygienists, TLV/BEI Resources. 2011. “American Conference of Governmental Industrial Hygienists $\mathrm{OH}$, US”. Accessed in October 10, 2014. http://www.acgih.org/tlv.

[21] National Institute for Occupational Safety and Health (NIOSH). Criteria for a recommended standard: 
Occupational noise exposure. Revised criteria 1998. Cincinnati, $\quad$ OH, NIOSH, 1998. http://www.cdc.gov/niosh/docs/98-126/pdfs/98-126.pdf.

[22] OSHA. 1983 "Occupational Noise Exposure: Hearing Conservation Amendment.” Federal Register. Occupational Safety and Health Administration (OSHA), 48: 9738-83.

[23] EU. 2003. "EC of the European Parliament and of the Council of 6th February 2003 on the Minimum Health and Safety Requirements Regarding the Exposure of Workers to the Risks Arising from Physical Agents (Noise).” DOUE: February.
[24] Occupational Safety and Health Administration (OSHA). Occupational noise exposure. Standard No. 1926. 52. Accessed in October 10, 2014. https://www.osha.gov/pls/oshaweb/owadisp.show_docum ent?p_table=STANDARDS\&p_id=10625.

[25] National Academy of Engineering, The Bridge. Fall 2007. Noise Engineering. Accessed in October 10, 2014 https://www.nae.edu/File.aspx?id=7411.

[26] Zalewski, E. 2006. "Noise Control: It's More than Just Earplugs. ” EHS Today. Accessed in October, 10, 2014. https://ehstoday.com/ppe/hearing-protection/ehs_imp_38 485. 